Research Article Human and Medical Genetics

\title{
$X R C C 4$ rs28360071 intronic variant is associated with increased risk for infant acute lymphoblastic leukemia with KMT2A rearrangements
}

\author{
Orlando Louzada-Neto ${ }^{1}$, Bruno A. Lopes ${ }^{2}$, Gisele D. Brisson ${ }^{2}$, Francianne G. Andrade ${ }^{2}$, Ingrid S. Cezar ${ }^{2}$, \\ Cíntia B. Santos-Rebouças ${ }^{3}$, Rodolpho M. Albano' ${ }^{1}$, Maria S. Pombo-de-Oliveira ${ }^{2}$ and Ana Rossini ${ }^{1}$ \\ ${ }^{1}$ Universidade do Estado do Rio de Janeiro, Departamento de Bioquímica, Laboratório de Toxicologia \\ e Biologia Molecular, Rio de Janeiro, RJ, Brazil. \\ ${ }^{2}$ Centro de Pesquisas, Instituto Nacional do Câncer, Programa de Hematologia-Oncologia Pediátrica, \\ Rio de Janeiro, RJ, Brazil. \\ ${ }^{3}$ Universidade do Estado do Rio de Janeiro, Departamento de Genética, Rio de Janeiro, RJ, Brazil.
}

\begin{abstract}
Early age acute leukemia (EAL) shows a high frequency of KMT2A-rearrangements (KMT2A-r). Previous investigations highlighted double-strand breaks arising from maternal exposure to xenobiotics during pregnancy as a risk factor for EAL and $K M T 2 A-r$. In this case-control study, we investigated the relationship between EAL and genetic variants of the nonhomologous end-joining (XRCC6 rs5751129, XRCC4 rs6869366 and rs28360071), since they might affect DNA repair capacity, leading to $K M T 2 A-r$ and leukemogenesis. Samples from 577 individuals (acute lymphoblastic leukemia-ALL, $n=164$; acute myeloid leukemia-AML, $n=113$; controls, $n=300$ ) were genotyped. No significant association was found for rs5751129 and rs6869366, whereas rs28360071 was associated with an increased risk for ALL with KMT2A-r (IIxID: OR - Odds ratio 2.23, Cl 1.17-4.25, $p=0.014$ ). Bone marrow samples from ALL patients showed a higher expression of XRCC4 compared to AML patients $(p=0.025)$. Human Splicing Finder 3.1 predicted that the deleted allele of rs 28360071 is potentially associated with the activation of a 5 ' cryptic splice site in intron 3 of XRCC4. The sequencing of CDNA did not show any differences on the splicing process for the rs28360071 genotypes. Our results suggest that the deleted allele for rs28360071 increases the risk for ALL with $K M T 2 A-r$, but not by modifying the XRCC4 expression levels or its structure.
\end{abstract}

Keywords: Early age acute leukemia, nonhomologous end-joining, XRCC4, XRCC6, KMT2A.

Received: May 26, 2020; Accepted: October 20, 2020.

\section{Introduction}

Early age acute leukemia (EAL) here defined as children aged up to 24 months old at the diagnosis) is a heterogeneous group of hematopoietic malignancies that includes neonatal and infant leukemia and is the leading cause of death by neoplastic diseases in this age group (Noone et al., 2018). The etiology of EAL might be related to an interplay between individual genetic susceptibility and exposure to genotoxic agents with potential carcinogenic action (Alexander et al., 2001; Pombode-Oliveira and Andrade, 2016). Common somatic aberrations found in EAL are rearrangements involving the $K M T 2 A$ gene (Lysine K-specific Methyltransferase 2A, also named Mixed Lineage Leukemia, MLL) (Felix, 2001). Since the KMT2A protein plays an essential role in the positive regulation of gene expression during human fetal development and hematopoiesis, (KMT2A-r - KMT2A rearranged) promotes both infant acute lymphoblastic leukemia (ALL - Acute lymphoblastic leukemia) and infant acute myeloid leukemia (AML) (Slany, 2009).

Translocations can occur after the generation of doublestrand breaks (DSB - Double strand break) along one or more chromosomes and incorrect chromosomal rejoining. Several

Send correspondence to Ana Rossini. Universidade do Estado do Rio de Janeiro, Departamento de Bioquímica, Laboratório de Toxicologia e Biologia Molecular, Rio de Janeiro, RJ, Brazil. E-mail: anartc @ gmail.com. studies have highlighted that KMT2A-r generation occurs inutero (Greaves and Wiemels, 2003). The association between EAL, $K M T 2 A$-r and maternal exposure to substances that can cross the placental barrier and cause DSBs in fetal DNA has been reported in epidemiological studies (Hutt and Kalf, 1996; Alexander et al., 2001; Pombo-de-Oliveira and Koifman, 2006). In the absence of proper DNA repair mechanisms, the maintenance of genomic integrity after exposure to these compounds would be affected, thus increasing the risk of $K M T 2 A$-r and EAL.

In eukaryotic cells, DSBs are primarily repaired by nonhomologous end-joining (NHEJ), which might occur in two different pathways: canonical NHEJ (c-NHEJ) and alternative NHEJ (a-NHEJ - Alternative non-homologous end-joining) (Deriano and Roth, 2013). C-NHEJ starts with the recognition of the extremities of DSBs by the heterodimer formed by $\mathrm{Ku} 70$ and $\mathrm{Ku} 80$ proteins, encoded by the genes $X R C C 6$ and XRCC5, respectively. Another central element involved in c-NHEJ is XRCC4 (X-Ray Cross Complementing 4), which encodes a core harbor protein that activates and leads DNA Ligase IV (LIG4) to the damage site to rejoin the strands (Lieber, 2008). However, a-NHEJ occurs in the absence of some c-NHEJ (Canonical non-homologous endjoining) central elements, including Ku70/80 and XRCC4 proteins, and it is considered an error-prone and unfaithful repair mechanism, potentially leading to the formation of 
deletions and chromosome translocations (Kabotyanski et al., 1998; Simsek and Jasin, 2010).

The aim of the present study was to conduct the first investigation focusing on the relationship between XRCC6 rs5751129, XRCC4 rs6869366, and XRCC4 rs28360071 polymorphisms and the risk for developing EAL with $K M T 2 A$-r. The rs5751129 is a single nucleotide polymorphism (SNP) within the promoter region of $X R C C 6$, which was previously proved to modulate the risk of other cancer types, probably by lowering the mRNA expression levels (Jia et al., 2015). The XRCC4 rs6869366 is also a SNP located at the promoter region, whereas rs 28360071 represents a $30 \mathrm{bp}$ deletion/insertion within intron 3 of $X R C C 4$. The implications of these later variants remain to be clarified. However, both are associated with increased risk for several cancer types, including acute childhood leukemia (Wu et al., 2010; Shao et al., 2013; Jin et al., 2019; Gupta et al., 2020).

\section{Material and Methods}

\section{Subjects}

In total, 277 samples (164 ALL and 113 AML cases) from Brazilian infants and toddlers (ages $<24$ months at the diagnosis of acute leukemia) were included in this study. These samples were obtained from the Brazilian Collaborative Study Group of Infant Acute Leukemia studies (2000-2013) (Pieters, 2009). DNA samples from the umbilical cord blood of healthy subjects $(n=300)$ were genotyped as controls. EAL encompasses a group of leukemias that affect neonates ( $\leq 31$ days), infants ( $\leq 12$ months), and toddlers (up to 24 months). Our EAL cohort was composed of infant-ALL, which is defined when leukemia diagnosis occurred in children $\leq 12$ months-old, based on its distinct clinical characteristics, such as pro-B immunophetotype $\left(\mathrm{CD} 10^{\text {neg }}\right)$ as well as high frequency of $K M T 2 A-r$. On the other hand, the time-frame for AML inclusion was extended to $\leq 24$ months of age at diagnosis, given that $K M T 2 A-r$ are more evenly distributed between infants and toddlers with this leukemia subtype (Pieters, 2009; Creutzig et al., 2012; Emerenciano et al., 2013). In the present study, the exclusion criteria for cases were T-cell precursor ALL, non-hematological or hematological malignancy syndromes with genetic alterations, such as Noonan Syndrome and Down Syndrome, and Myelodysplasic Syndrome. EAL patients with insufficient or low DNA quality samples and without parental consent were excluded from the study.

The diagnosis of acute leukemia subtypes was applied throughout bone marrow morphology, immunophenotyping, and molecular-cytogenetic alterations, according to World Health Organization criteria (Arber et al., 2016).

The race/ethnicity was defined according to the Instituto Brasileiro de Geografia e Estatística (IBGE), which gathers subjects according to skin color self-definition. The subjects were categorized into whites or non-whites. The group of non-whites comprised self-categorized brown or Africandescent subjects.

The present study was approved by the Ethics and Scientific Committee of the Instituto Nacional de Câncer (CEP-CONEP \# 626.268; April 24 ${ }^{\text {th }}, 2014$ ).

\section{KMT2A status analysis}

Bone marrow RNA extraction, cDNA synthesis, and quantitative polymerase chain reaction (qPCR) were performed as described elsewhere (Lopes et al., 2015). Briefly, RNA was extracted from bone marrow samples using TRIzol reagent (Invitrogen, CA, USA) according to the manufacturer's instructions. Following DNase treatment (Invitrogen, CA, USA), cDNA was synthesized using SuperScript III Reverse Transcriptase (Invitrogen, CA, USA) with $3 \mu \mathrm{g}$ of purified RNA as a template. $K M T 2 A$ status was evaluated by reverse transcription-PCR assays for the detection of the main chimeric transcripts (fusion between KMT2A and AFF1, MLLT3, MLLT1, MLLT10, or MLLT4), and/or by fluorescence in situ hybridization (Vysis LSI MLL Dual Color, Break Apart Rearrangement Probe, Abbott Laboratories, Abbot Park, IL, USA) as previously described (Emerenciano et al., 2006; Burmeister et al., 2015).

\section{DNA extraction and genotyping}

DNA extraction was performed with the QIAamp DNA Mini kit (Qiagen Inc., Germantown, MD, USA) according to the manufacturer's protocols. Genotyping was performed by PCR, followed by restriction fragment length polymorphism (RFLP) for XRCC6 rs5751129 (informally cited as -991 T $>$ C) and XRCC4 rs6869366 (informally cited as $-1394 \mathrm{~T}>\mathrm{G}$ ) according to a previous report (Tsai et al., 2007). Subsequently, the alleles of insertion (139 bp) and deletion (109 bp) of XRCC4 rs28360071 (informally cited as intron 3 DIP) were detected by $2 \%$ agarose gel electrophoresis.

\section{Gene expression}

We evaluated $X R C C 4 \mathrm{mRNA}$ expression in 42 samples (25 ALL and 17 AML) by qPCR using the following primer sequences: 5'- TGGACTGGGACAGTTTCTGA-3' (forward) and 5'- CTGCTCCTGACAACAATGCT- 3' (reverse), as previously described (Shao et al., 2014). The glyceraldehyde 3-phosphate dehydrogenase (GAPDH) gene was used for the normalization of XRCC4 transcript using the 5'-CAACAGCCTCAAGATCATCAGCAA-3' (forward) and 5'-AGTGATGGCATGGACTGTGGTCAT-3' (reverse) primers. The experiments were performed in triplicates, and $\mathrm{Ct}$ medians were used to determine the relative expression by the $2^{-\Delta C t}$ method (Livak and Schmittgen, 2001).

\section{Sequencing}

For evaluating if the splicing process is different among the three genotypes for rs28360071, a pair of primers on exon 3 (Forward: 5'-GGAGCAGGACCAGCTGATGTAT-3') and exon 4 (Reverse: 5'-TTTCTGCAATGGTGTCCAAGC-3') of XRCC4 cDNA was designed. After that, cDNA samples from five random patients (two carrying II, one carrying ID (Insertion/Deletion. Heterozygous genotype of rs28360071) and two carrying DD (Deletion/Deletion. Homozygous genotype of deletion allele of rs28360071) genotypes) were amplified by PCR. The amplified fragment resulting from the splicing process was expected as a $175 \mathrm{bp}$ fragment (Figure S3b). PCR fragments were purified using Agencourt AMPure XP magnetic beads (Beckman Coulter Company, 
MA, USA), and sequenced with the BigDye Terminator v3.1 Cycle Sequencing Kit (Thermo Fisher Scientific Inc.) on a 3500 Genetic Analyser (Thermo Fisher Scientific Inc.). Experiments were performed in triplicates. Representative chromatograms are shown in Figure S3.

\section{Statistical and in silico analysis}

The chi-square test was used for the comparison of sociodemographic frequencies between cases and controls, such as child age, sex, ethnicity/skin color, and KMT2A status. Expected genotypes frequencies of the genetic polymorphisms were calculated by Hardy-Weinberg (HW) with GenePop Web version 4.5.1 (http://genepop.curtin.edu. $\mathrm{au} /$ ). The Odds Ratios (ORs) with $95 \%$ confidence intervals (CI) were calculated using chi-square and the Fisher's exact tests. Disease risk was calculated for dominant (wild-type homozygote vs. polymorphic heterozygote + polymorphic homozygote), recessive (wild-type homozygote + heterozygote vs. polymorphic homozygote), codominant (wild-type homozygote vs. heterozygote or wild-type homozygote vs. polymorphic homozygote), and additive (wild-type homozygote vs. heterozygote + two times polymorphic homozygote) models. The Statistical Product and Services Solutions statistical package 22.0 (SPSS Inc., Chicago, IL, USA) was used to calculate odds ratios (ORs) with 95\% confidence intervals (CIs) and $p$ values while unconditional logistic regression was used to estimate adjusted odds ratios (aORs). For all analyses, the $p$ values $<0.05$ were considered significant. Bonferroni correction for testing three SNPs was applied to the adjusted $p$ value. The Bonferroni-corrected statistical significance level set at $p$ values $<0.017(0.05 / 3)$ indicated statistically significant results. The qPCR statistical analysis was performed with GraphPad Prism 5 (GraphPad Software, Inc., California, USA). The comparison among genotypes in relation to $X R C C 4$ expression was performed using the Kruskal-Wallis tests. The Mann-Whitney test was used for analyses related to KMT2A status.

The online bioinformatics tool Human Splicing Finder version 3.1 software http://www.umd.be/HSF3/index.html (HSF, 2019) was applied to predict the potential functional impact of the indel polymorphism at XRCC4 splicing sites. This software is an international reference that combines twelve different algorithms to identify and predict the effect of a variant on splicing motifs, including the acceptor and donor splice sites, the branch point, and auxiliary sequences known to either enhance or repress splicing.

\section{Results}

\section{XRCC4 deleted allele rs28360071 increases the risk for ALL in patients with KMT2A-r}

The frequency distribution of demography characteristics, childhood leukemia subtypes, and KMT2A status are described in Table 1 . The children were $\leq 2$ years old at the diagnosis of acute leukemia, with a mean age of $13 \pm 5.6$ months at the time of diagnosis $(\mathrm{ALL}=12 \pm 7.0$ months and $\mathrm{AML}=13 \pm$ 5.7 months). The distribution of cases and controls by sex was similar, but regarding to ethnicity, there was a higher number of whites in both groups $(\mathrm{p}=0.010)$. All genotype distribution of polymorphisms was in Hardy-Weinberg equilibrium (Table S1).

Table 1 - The frequency distribution of childhood leukemia, demography and KMT2A status, Brazil, 2000-2013.

\begin{tabular}{|c|c|c|c|}
\hline & $\begin{array}{l}\text { Cases } \\
\mathrm{n}(\%)\end{array}$ & $\begin{array}{c}\text { Controls } \\
\text { n }(\%)\end{array}$ & $p$ Value \\
\hline \multicolumn{4}{|c|}{ Acute Leukemia Subtype } \\
\hline ALL & $164(59.2)$ & - & - \\
\hline AML & $113(40.8)$ & - & \\
\hline \multicolumn{4}{|l|}{ Sex } \\
\hline Male & $147(53.5)$ & $144(48.0)$ & 0.211 \\
\hline Female & $128(46.5)$ & $156(52.0)$ & \\
\hline NI & 2 & 0 & \\
\hline \multicolumn{4}{|l|}{ Ethnicity } \\
\hline White & $164(60.3)$ & $136(49.0)$ & 0.010 \\
\hline Non-white* & $108(39.7)$ & $142(51.0)$ & \\
\hline NI & 5 & 22 & \\
\hline \multicolumn{4}{|l|}{$K M T 2 A$ Status } \\
\hline$K M T 2 A-r$ & $103(48.1)$ & - & - \\
\hline$K M T 2 A-W T$ & $111(51.9)$ & - & \\
\hline NI & 63 & - & \\
\hline Total & $277(48.0)$ & $300(52.0)$ & - \\
\hline
\end{tabular}

ALL: Acute Lymphoblastic Leukemia; AML: Acute Myeloid Leukemia; NI: No Information available; KMT2A-r: KMT2A rearranged; KMT2A-WT: KMT2A wild type.

(*) Comprises Brazilians with genetic admixture and self-defined skin color. 
No significant association between the XRCC6 rs5751129 variant and EAL risk was observed in any analyzed parameter (Table S2). The XRCC4 6869366 variant demonstrated a protective effect on $K M T 2 A$-r only among ALL cases under the dominant $(\mathrm{OR}=0.30 ; \mathrm{CI}=0.09-1.00 ; p=0.040)$ and additive $(\mathrm{OR}=0.30 ; \mathrm{CI}=0.10-0.95 ; p=0.040)$ models (Table S3). However, the statistical significance of those associations was lost by adjusting OR by skin color and sex (dominant model: $\mathrm{aOR}=0.30 ; \mathrm{CI}=0.08-1.01 ; p=0.054$ and additive model: $\mathrm{aOR}=0.42 ; \mathrm{CI}=0.01-1.11 ; p=0.050)$. However, for the $X R C C 4$ rs28360071 an increased risk for ALL with KMT2A-r was associated with the heterozygous genotype (Codominant model; homozygous for insertion II vs. heterozygous ID: $\mathrm{OR}=2.00 ; \mathrm{CI}=1.10-3.80 ; p=0.039)$, even when adjusted $(\mathrm{aOR}=2.23 ; \mathrm{CI}=1.17-4.25 ; p=0.014)($ Table 2$)$. The results remained statistically significant after Bonferroni's correction $(\mathrm{p}=0.014 \times 3=0.042)$.

\section{There is a higher expression of XRCC4 in ALL patients}

Due to the observed association of XRCC4 and ALL, $X R C C 4$ mRNA expression levels in the bone marrow of patients was evaluated by qPCR. A higher expression of $X R C C 4$ was found in ALL compared to AML $(p=0.025)$ (Fig. 1a). No differential expression was observed according to the three genotypes for the $X R C C 4$ rs28360071 polymorphism (Fig. $1 \mathrm{~b})$, even when the data were stratified by $K M T 2 A$ status. However, $K M T 2 A$-r samples seem to show slightly higher $X R C C 4$ expression than that in KMT2A wild type (KMT2AWT - KMT2A wild type) samples $(p=0.080)$ (Fig. 1c). Moreover, no differential expression was observed according to either genotypes or KMT2A status in both ALL and AML (Figure S1).

\section{The splicing process of XRCC4 could be altered due to rs28360071}

In silico analysis performed by HSF predicted three changes on intron 3 , caused by the deletion of 30 base pairs and activation of an intronic cryptic donor site, an alteration of a splicing silencer site, and the creation of a splicing enhancer site. From those changes, the former was interpreted by the software as having a potential impact on splicing with a high score (Figure S2). We have performed direct sequencing of $X R C C 4$ in bone marrow cDNA samples, and no structural alterations in cDNA lengths were observed, regardless of the XRCC4 rs28360071 genotype status (Figure S3).

\section{Discussion}

In the present study, the correlation between genetic polymorphisms in NHEJ genes and the risk for EAL was evaluated. No correlation was found between the overall risk for EAL with KMT2A-WT and XRCC4 (rs6869366 and rs28360071) or XRCC6 (rs5751129) variants included here.

The XRCC6 rs5751129 SNP is associated with decreased transcript and protein expression levels (Hsu et al., 2013). Individuals carrying the ${ }^{*} \mathrm{C}$ allele had lower XRCC6 mRNA expression (Chang et al., 2012; Hsu et al., 2013). Regarding acute childhood leukemia (0-18 years old), patients carrying the heterozygous genotype had a significantly increased risk of developing the disease (Pei et al., 2013). In the present work, no association between rs5751129 and EAL was found, regardless $K M T 2 A$ status.

$\mathrm{Wu}$ and colleagues found an increased risk of leukemia related to both $X R C C 4$ variants among Taiwanese children (Wu et al., 2010). These authors found that ${ }^{*} \mathrm{G}$ and deleted alleles of XRCC4 rs6869366 and rs28360071, respectively, are associated with a higher risk for childhood leukemia. The present study demonstrates that the $* \mathrm{~T}$ allele of XRCC4 rs6869366 has a protective effect against ALL, although the association was not significant after p-value adjustment. Another study showed that $\mathrm{XRCC4}$ variants are associated with an increased risk for ALL, particularly in ALL cases with chromosomal translocations and hyperdiploidy, both alone and in conjunction with exposure to ionizing radiation (Chokkalingam et al., 2011).

Here, an increased risk for ALL with $K M T 2 A-r$ was found to be associated with the ID genotype of XRCC4 rs28360071. These data suggest an influence of the 30-bp deletion allele over the XRCC4 protein or its repair. Other studies have also shown significant associations between $X R C C 4$ variants and childhood ALL with ETV6-RUNXI $[\mathrm{t}(12 ; 21)]$ translocations (Chokkalingam et al., 2011). To examine whether the deletion allele could be related to gene expression levels, XRCC4 mRNA expression was assessed by qPCR, showing higher expression in ALL than in AML samples. Although not statistically significant, KMT2A-r samples showed higher gene expression than that of $K M T 2 A-$ WT samples. Chiou and colleagues studied the expression of the genes related to NHEJ in samples from children with pediatric ALL (Chiou et al., 2007). These studies also showed an increased expression of XRCC4 mRNA. We did not find any variation of $X R C C 4$ expression associated with $X R C C 4$ rs28360071 genotypes, suggesting that the deletion allele could influence the risk for EAL by another mechanism. In this sense, the use of an in silico tool pointed out that the deleted allele could potentially implicate XRCC4 splicing, through activation of a cryptic donor site on intron 3. Cryptic splice sites are dormant or less used splicing sites found both in exons and introns that can be activated by mutations. When activated, these sites could be efficiently used by the splicing machinery, possibly resulting in genetic disorders (Buratti et al., 2007; Wang and Cooper, 2007). In the presence of the $30 \mathrm{bp}$ deletion in intron 3 of XRCC4, the activation of a cryptic donor splicing site may lead to preferential use of this donor site in detriment of the original one. As a consequence, this event can lead to the inclusion of part of intron 3 into the mature mRNA, which could cause protein structure modifications.

Additionally, the defective mRNA may also include a premature stop codon, which could even deflagrate degradation of the mRNA before translation by nonsense-mediated decay, as previously reported (Nicholson and Muhlemann, 2010; Santos-Rebouças et al., 2011). As no changes in the splicing process were observed by XRCC4 cDNA sequencing, we hypothesize that the influence of the rs 28360071 polymorphism on the development of EAL might occur by another biological mechanism. We are not able to determine the impact of this polymorphism on the biology of the protein and how it 
Table 2 - Genotype frequencies for XRCC4 rs28360071 in EAL subtypes and KMT2A status.

\begin{tabular}{|c|c|c|c|c|c|}
\hline$X R C C 4$ rs28360071 & $\begin{array}{l}\text { Control } \\
\mathrm{n}(\%)\end{array}$ & \multicolumn{2}{|c|}{$\begin{array}{l}\text { ALL } \\
\mathrm{n}(\%)\end{array}$} & \multicolumn{2}{|c|}{$\begin{array}{l}\text { AML } \\
\mathrm{n}(\%)\end{array}$} \\
\hline II & $87(30.3)$ & \multicolumn{2}{|c|}{$42(26.9)$} & \multicolumn{2}{|c|}{$35(31.5)$} \\
\hline ID & $134(46.7)$ & \multicolumn{2}{|c|}{$85(54.5)$} & \multicolumn{2}{|c|}{$50(45.0)$} \\
\hline DD & $66(23.0)$ & \multicolumn{2}{|c|}{$29(18.6)$} & \multicolumn{2}{|c|}{$26(23.4)$} \\
\hline Genetic Model & & $\begin{array}{c}p \\
\text { OR }(\mathrm{CI})\end{array}$ & $\begin{array}{c}p \\
\operatorname{aOR}(\mathrm{CI})\end{array}$ & $\begin{array}{c}p \\
\text { OR }(\mathrm{CI})\end{array}$ & $\begin{array}{c}p \\
\text { aOR (CI) }\end{array}$ \\
\hline Dominant & & $\begin{array}{c}0.510 \\
1.18(0.80-1.82)\end{array}$ & $\begin{array}{c}0.250 \\
1.07(0.75-1.55)\end{array}$ & $\begin{array}{c}0.810 \\
0.95(0.60-1.52)\end{array}$ & $\begin{array}{c}0.911 \\
0.97(0.59-1.58)\end{array}$ \\
\hline Recessive & & $\begin{array}{c}0.330 \\
0.80(0.50-1.25)\end{array}$ & $\begin{array}{c}0.247 \\
0.90(0.60-1.30)\end{array}$ & $\begin{array}{c}1.000 \\
1.02(0.61-1.72)\end{array}$ & $\begin{array}{c}0.830 \\
0.94(0.55-1.61)\end{array}$ \\
\hline II vs. ID & & $\begin{array}{c}0.251 \\
1.31(0.83-2.10)\end{array}$ & $\begin{array}{c}0.103 \\
1.14(0.80-1.70)\end{array}$ & $\begin{array}{c}0.800 \\
0.93(0.60-1.54)\end{array}$ & $\begin{array}{c}0.992 \\
0.99(0.58-1.68)\end{array}$ \\
\hline II vs. DD & & $\begin{array}{c}0.773 \\
0.91(0.51-1.61)\end{array}$ & $\begin{array}{c}0.931 \\
0.94(0.60-1.51)\end{array}$ & $\begin{array}{c}1.000 \\
1.00(0.54-1.80)\end{array}$ & $\begin{array}{c}0.837 \\
0.93(0.50-1.74)\end{array}$ \\
\hline Additive & & $\begin{array}{c}0.671 \\
1.11(0.73-1.70)\end{array}$ & $\begin{array}{c}0.379 \\
0.82(0.53-1.26)\end{array}$ & $\begin{array}{c}0.910 \\
0.95(0.60-1.50)\end{array}$ & $\begin{array}{c}0.870 \\
1.04(0.65-1.66)\end{array}$ \\
\hline \multicolumn{6}{|c|}{$K M T 2 A-\mathrm{WT}$} \\
\hline$X R C C 4$ rs 28360071 & $\begin{array}{l}\text { Control } \\
\mathrm{n}(\%)\end{array}$ & \multicolumn{2}{|c|}{$\begin{array}{l}\text { ALL } \\
\mathrm{n}(\%)\end{array}$} & \multicolumn{2}{|c|}{$\begin{array}{l}\text { AML } \\
\text { n }(\%)\end{array}$} \\
\hline II & $87(30.3)$ & \multicolumn{2}{|c|}{$19(30.6)$} & \multicolumn{2}{|c|}{$11(25.0)$} \\
\hline ID & $134(46.7)$ & \multicolumn{2}{|c|}{$28(45.2)$} & \multicolumn{2}{|c|}{$21(47.7)$} \\
\hline DD & $66(23.0)$ & \multicolumn{2}{|c|}{$15(24.2)$} & \multicolumn{2}{|c|}{$12(27.3)$} \\
\hline Genetic Model & & $\begin{array}{c}p \\
\text { OR }(\mathrm{CI})\end{array}$ & $\begin{array}{c}p \\
\operatorname{aOR}(\mathrm{CI})\end{array}$ & $\begin{array}{c}p \\
\text { OR }(\mathrm{CI})\end{array}$ & $\begin{array}{c}p \\
\operatorname{aOR}(\mathrm{CI})\end{array}$ \\
\hline Dominant & & $\begin{array}{c}1.000 \\
1.00(0.54-1.80)\end{array}$ & $\begin{array}{c}0.874 \\
0.95(0.51-1.74)\end{array}$ & $\begin{array}{c}0.600 \\
1.30(0.63-2.70)\end{array}$ & $\begin{array}{c}0.308 \\
0.67(0.31-1.44)\end{array}$ \\
\hline Recessive & & $\begin{array}{c}0.900 \\
1.10(0.60-2.03)\end{array}$ & $\begin{array}{c}0.937 \\
0.97(0.50-1.86)\end{array}$ & $\begin{array}{c}0.600 \\
1.30(0.61-2.60)\end{array}$ & $\begin{array}{c}5.053 \\
0.83(0.40-1.74)\end{array}$ \\
\hline II vs. ID & & $\begin{array}{c}1.000 \\
1.00(0.50-1.90)\end{array}$ & $\begin{array}{c}0.913 \\
0.96(0.50-1.85)\end{array}$ & $\begin{array}{c}0.700 \\
1.25(0.60-2.70)\end{array}$ & $\begin{array}{c}0.357 \\
0.68(0.30-1.54)\end{array}$ \\
\hline II vs. DD & & $\begin{array}{c}1.000 \\
1.04(0.50-2.20)\end{array}$ & $\begin{array}{c}0.850 \\
0.92(0.43-2.00\end{array}$ & $\begin{array}{c}0.501 \\
1.45(0.60-3.50)\end{array}$ & $\begin{array}{c}0.373 \\
0.66(0.26-1.64)\end{array}$ \\
\hline Additive & & $\begin{array}{c}1.000 \\
1.00(0.60-1.80)\end{array}$ & $\begin{array}{c}0.850 \\
0.94(0.52-1.69)\end{array}$ & $\begin{array}{c}0.502 \\
1.35(0.70-2.70)\end{array}$ & $\begin{array}{c}0.279 \\
0.66(0.31-1.39)\end{array}$ \\
\hline \multicolumn{6}{|c|}{$K M T 2 A-\mathrm{r}$} \\
\hline$X R C C 4$ rs28360071 & $\begin{array}{l}\text { Control } \\
\mathrm{n}(\%)\end{array}$ & \multicolumn{2}{|c|}{$\begin{array}{l}\text { ALL } \\
\mathrm{n}(\%)\end{array}$} & \multicolumn{2}{|c|}{$\begin{array}{l}\text { AML } \\
\text { n (\%) }\end{array}$} \\
\hline II & $87(30.3)$ & \multicolumn{2}{|c|}{$16(20.8)$} & \multicolumn{2}{|c|}{$10(43.5)$} \\
\hline ID & $134(46.7)$ & \multicolumn{2}{|c|}{$49(63.6)$} & \multicolumn{2}{|c|}{$9(39.1)$} \\
\hline DD & $66(23.0)$ & \multicolumn{2}{|c|}{$12(15.6)$} & \multicolumn{2}{|c|}{$4(17.4)$} \\
\hline Genetic Model & & $\begin{array}{c}p \\
\text { OR }(\mathrm{CI})\end{array}$ & $\begin{array}{c}p \\
\operatorname{aOR}(\mathrm{CI})\end{array}$ & $\begin{array}{c}p \\
\text { OR }(\mathrm{CI})\end{array}$ & $\begin{array}{c}p \\
\operatorname{aOR}(\mathrm{CI})\end{array}$ \\
\hline Dominant & & $\begin{array}{c}0.120 \\
1.70(0.91-3.04\end{array}$ & $\begin{array}{c}0.057 \\
1.81(0.98-3.37)\end{array}$ & $\begin{array}{c}0.242 \\
0.60(0.24-1.34)\end{array}$ & $\begin{array}{c}0.333 \\
0.64(0.26-1.57)\end{array}$ \\
\hline Recessive & & $\begin{array}{c}0.210 \\
0.62(0.32-1.21)\end{array}$ & $\begin{array}{c}0.150 \\
0.60(0.30-1.19)\end{array}$ & $\begin{array}{c}0.800 \\
0.70(0.23-2.15)\end{array}$ & $\begin{array}{c}0.602 \\
0.74(0.24-2.28)\end{array}$ \\
\hline II vs. ID & & $\begin{array}{c}0.039 \\
2.00(1.10-3.80)\end{array}$ & $\begin{array}{c}0.014 \\
2.23(1.17-4.25)\end{array}$ & $\begin{array}{c}0.331 \\
0.60(0.23-1.50)\end{array}$ & $\begin{array}{c}0.434 \\
0.67(0.25-1.79)\end{array}$ \\
\hline II vs. DD & & $\begin{array}{c}1.000 \\
1.00(0.44-2.23)\end{array}$ & $\begin{array}{c}0.900 \\
1.06(0.46-2.45)\end{array}$ & $\begin{array}{c}0.400 \\
0.53(0.16-1.80\end{array}$ & $\begin{array}{c}0.393 \\
0.58(0.16-2.01)\end{array}$ \\
\hline Additive & & $\begin{array}{c}0.210 \\
1.50(0.82-2.70)\end{array}$ & $\begin{array}{c}0.115 \\
0.61(0.33-1.12)\end{array}$ & $\begin{array}{c}0.171 \\
0.60(0.25-1.30)\end{array}$ & $\begin{array}{c}0.276 \\
1.60(0.68-3.76)\end{array}$ \\
\hline
\end{tabular}

ALL: Acute Lymphoblastic Leukemia; AML: Acute Myeloid Leukemia; OR: Odds ratio; aOR: Odds ratio adjusted by skin color and sex; KMT2A-WT: $K M T 2 A$ wild type; KMT2A-r: KMT2A rearranged; II: homozygous for insertion; ID: heterozygous; DD: homozygous for deletion. 

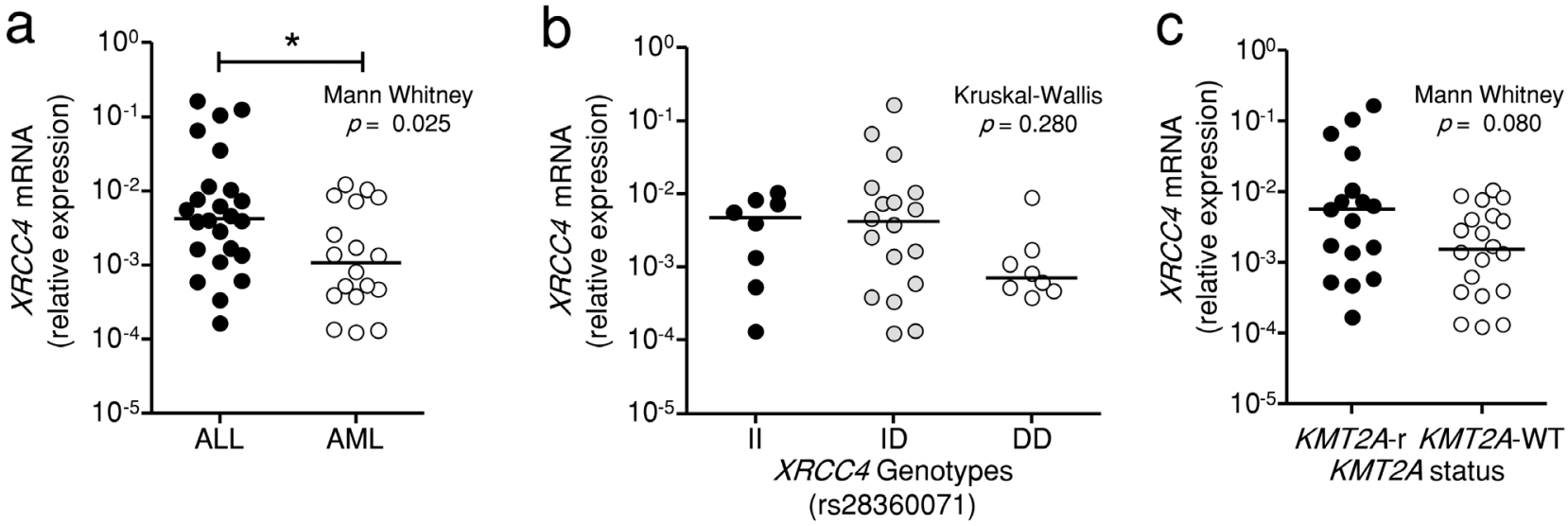

Figure 1 - Differential levels of $X R C C 4$ mRNA in EAL bone marrow samples. (a) Comparison of the expression levels of $X R C C 4$ in acute lymphoblastic leukemia (ALL) and acute myeloid leukemia (AML). (b) Differential levels of XRCC4 according to the genotypes for the $X R C C 4$ rs 28360071 polymorphism. (c) Comparison of XRCC4 expression levels in patients harboring $K M T 2 A$ rearranged $(K M T 2 A-r)$ and $K M T 2 A$ wild type $(K M T 2 A$-WT). Experiments were performed in triplicates. Horizontal bars indicate median values.

implicates on NHEJ repair capacity with the data we showed here. Future studies are needed to investigate the molecular mechanisms underlying the phenotypic impact caused by rs28360071.

The present results are not similar to those reported by other groups studying pediatric acute leukemia. This discrepancy is likely due to the characteristic of the study population since the present work includes a unique series of children up to 24 months old, and most studies regarding childhood leukemia include children up to 18 years old. The disease development of EAL is related to a prenatal origin, resulting from in utero exposure to DNA damage agents. In contrast, the disease among older children can have a different etiology, including the acquisition of additional genetic aberrations during childhood. Since other studies do not analyze ALL and AML separately, a comparison of the results between studies should be performed carefully. Indeed, we must consider that the Brazilian population has unique miscegenation profile and is one of the most heterogeneous populations worldwide (Parra et al., 2003).

Herein, we assessed the influence of genetic polymorphisms in central elements of c-NHEJ on the development of EAL and KMT2A-r. Our hypothesis was based on the fact that maternal exposure to xenobiotic compounds generates DSBs on DNA of fetal hematological stem cells. Once DNA repair is not appropriate, chromosomal translocations could occur within $K M T 2 A$, thus driving and sustaining in utero leukemogenesis.

To the best of our knowledge, this study is the first to report polymorphisms in the NHEJ repair system and $K M T 2 A$-r in EAL. Although the risk for EAL was not related to $X R C C 6$ rs 5751129 or XRCC4 rs6869366 variants, the 30 -bp deletion within the third intron of $X R C C 4$ influenced the risk of ALL with $K M T 2 A$-r cases. Additional studies are necessary to evaluate the functional impact of these variants in the biology of leukemia.

\section{Acknowledgments}

This research was financially supported through a grant from the FAPERJ $\neq \mathrm{E} \_26 / 110.169 / 2013$; MSPO is a CNPq scholar $\neq 301594 / 2015-5$. This study was financed in part by the Coordenação de Aperfeiçoamento de Pessoal de Nível Superior - Brasil (CAPES) - Finance Code 001. We would like to thank Bruno A. Gonçalves, Camilla G. Andrade, Caroline B. Blunk, Gisele M. Vasconcelos, Eugenia T. Granado and Denise N. de Oliveira for technical support. We would also like to thank the members of the Brazilian Collaborative Study Group of Infant Acute Leukemia who contributed for the present study: Eugênia T. Granado, Elda Noronha, Bruno Aguiar, Gisele M. Vasconcelos and Paulo Neto from the PHOP-CPq, INCa, Rio de Janeiro for thecnical support and the physicians who sent samples along with clinical data from the patients (Sidnei Epelman and Renato Guedes from Hospital Santa Marcelina, São Paulo, Maura Ikeda and Teresa Cristina Oliveira from Hospital Amaral Carvalho, São Paulo, Eloisa C. Fialho from Hospital Napoleão Laureano, Paraíba, Gustavo R. Neves from Hospital Sarina Rolin, São Paulo, Isis Maria Q. Magalhães, José Carlos Córdoba and Ricardo Camargo from Hospital da Criança de Brasília José Alencar, Brasília, Patricia C. de Brito and Anna Carolina S. Dias, Hospital Araújo Jorge, Goiás, Juliana T. Costa and Luciana N. S. Souza from Hospital Martagão Gesteira, Bahia, Marcelo S. Santos and Rosania Basegio from Centro de Tratamento Onco-hematológico Infantil de Mato Grosso do Sul, Mato Grosso do Sul and Teresa Cristina Cardoso-Fonseca from Santa Casa de Misericórdia de Itabuna, Bahia).The head of the group is Dr Maria S. Pombo-de-Oliveira.

\section{Conflicts of Interest}

The authors declare no conflict of interest.

\section{Authors Contributions}

MSPO and AR conceived and the study; OLN conducted the experiments; OLN, MSPO, and AR analyzed the data; OLN, BAL, GBD, FGA, ISC, CBSR, RMA, MSPO and AR collected data, contributed to the discussion and reviewed the manuscript; OLN and AR wrote the manuscript, all authors read and approved the final version. 


\section{References}

Alexander FE, Patheal SL, Niondi A, Brandalise S, Cabrera ME, Chan LC, Chen Z, Cimino G, Cordoba JC, Gu LJ et al. (2001) Transplacental Chemical Exposure and Risk of Infant Leukemia with MLL Gene Fusion. Cancer Res 61:2542-2546.

Arber DA, Orazi A, Hasserjian R, Thiele J, Borowitz MJ, Le Beau MM, Bloomfield CD, Cazzola M and Vardiman JW (2016) The 2016 revision to the World Health Organization classification of myeloid neoplasms and acute leukemia. Blood 127:2391-2406.

Buratti E, Chivers M, Královicová J, Romano R, Baralle M, Krainer AR and Vořechovský I (2007) Aberrant 5' splice sites in human disease genes: Mutation pattern, nucleotide structure and comparison of computational tools that predict their utilization. Nucleic Acids Res 35:4250-4263.

Burmeister T, Meyer C, Gröger D, Hofmann J and Marschalek R (2015) Evidence-based RT-PCR methods for the detection of the 8 most common MLL aberrations in acute leukemias. Leuk Res 39:242-247.

Chang WS, Ke HL, Tsai CW, Lien CS, Liao WL, Lin HH, Lee MH, Wu HC, Chang CH, Chen CC et al. (2012) The role of XRCC6 T-991C functional polymorphism in renal cell carcinoma. Anticancer Res 32:3855-3860.

Chiou SS, Huang JL, Tsai YS, Chen TF, Lee KW, Juo SH, Jong YJ, Hung CH, Chang TT, Lin CS (2007) Elevated mRNA transcripts of non-homologous end-joining genes in pediatric acute lymphoblastic leukemia. Leukemia 21:2061-2064.

Chokkalingam AP, Bartley K, Wiemels JL, Metayer C, Barcellos LF, Hansen HM, Aldrich MC, Guha N, Urayama KY, Scélo G et al. (2011) Haplotypes of DNA repair and cell cycle control genes, $\mathrm{X}$-ray exposure, and risk of childhood acute lymphoblastic leukemia. Cancer Causes Control 22:1721-1730.

Creutzig U, van den Heuvel-Eibrink MM, Gibson B, Dworzak MN, Adachi S, de Bont E, Harbott J, Hasle H, Johnston D, Kinoshita A et al. (2012) Diagnosis and management of acute myeloid leukemia in children and adolescents: recommendations from an international expert panel. Blood 120:3187-3205.

Deriano L and Roth DB (2013) Modernizing the Nonhomologous End-Joining Repertoire: Alternative and classical NHEJ share the stage. Annu Rev Genet 47:433-455.

Emerenciano M, Agudelo Arias DP, Coser VM, de Brito GD, Macedo Silva ML, Pombo-de-Oliveira M and Brazilian Collaborative Study Group of Infant Acute Leukemia (2006) Molecular cytogenetic findings of acute leukemia included in the Brazilian Collaborative Study Group of Infant Acute Leukemia. Pediatr Blood Cancer 47:549-554.

Emerenciano M, Meyer C, Mansur MB, Marschalek R, Pombode-Oliveira MS and Brazilian Collaborative Study Group of Infant Acute Leukaemia (2013) The distribution of MLL breakpoints correlates with outcome in infant acute leukaemia. Br J Haematol 161:224-236.

Felix CA (2001) Leukemias related to treatment with DNA topoisomerase II inhibitors. Med Pediatr Oncol 36:525-535.

Greaves MF and Wiemels J (2003) Origins of chromosome translocations in childhood leukaemia. Nat Rev Cancer 3:639-349.

Gupta MK, Kushwah AS, Singh R and Banerjee M (2020) Genotypic analysis of XRCC4 and susceptibility to cervical cancer. $\mathrm{Br}$ J Biomed Sci 77:7-12.

Hsu CM, Yang MD, Chang WS, Jeng LB, Lee MH, Lu MC, Chang SC, Tsai CW, Tsai Y, Tsai FJ et al. (2013) The contribution of XRCC6/Ku70 to hepatocellular carcinoma in Taiwan. Anticancer Res 33:529-539.
Hutt AM and Kalf GF (1996) Inhibition of Human DNA Topoisomerase II by hydroquinone and p-benzoquinone, reactive metabolites of benzene. Environ Heal Perpectives 104:1265-1269.

Jia J, Ren J, Yan D, Xiao L and Sun F (2015) Association between the XRCC6 polymorphism and cancer risks: A systematic review and meta-analysis. Medicine 94:1-15.

Jin D, Zhang M and Hua H (2019) Impact of polymorphisms in DNA repair genes XPD, hOGG1 and XRCC4 on colorectal cancer risk in a Chinese Han Population. Biosci Rep 15:1-9.

Kabotyanski EB, Gomelsky L, and Han JO, Stamato TD and Roth DB (1998) Double-strand break repair in Ku86-and XRCC4deficient cells. Nucleic Acids Res 26:5333-5342.

Lieber MR (2008) The mechanism of human nonhomologous DNA end joining. J Biol Chem 283:1-5.

Livak KJ and Schmittgen TD (2001) Analysis of relative gene expression data using real-time quantitative PCR and the 2- $\Delta \Delta \mathrm{Ct}$ method. Methods 25:402-408.

Lopes BA, Emerenciano M, Gonçalves BA, Vieira TM, Rossini A and Pombo-de-Oliveira MS (2015) Polymorphisms in CYP1B1, CYP3A5, GSTT1, and SULT1A1 are associated with early age acute leukemia. PLoS One 10:e0127308.

Nicholson P and Mühlemann O (2010) Cutting the nonsense: the degradation of PTC-containing mRNAs. Biochem Soc Trans 38:1615-1620.

Noone AM, Howlader N, Krapcho M, Miller D, Brest A, Yu M, Ruhl J, Tatalovich Z, Mariotto A, Lewis DR et al. (2018) SEER Cancer Statistics Review, 1975-2015, National Cancer Institute, https://seer.cancer.gov/archive/csr/1975_2015/

Parra FC, Amado RC, Lambertucci JR, Rocha J, Antunes CM and Pena SD (2003) Color and genomic ancestry in Brazilians. Proc Natl Acad Sci USA 100:177-182.

Pei JS, Lee YIM, LO HH, Hsu YN, Lin SS and Bau DT (2013) Association of X-ray repair cross-complementing-6 genotypes with childhood leukemia. Anticancer Res 33:5395-5400.

Pieters R (2009) Infant acute lymphoblastic leukemia: Lessons learned and future directions. Curr Hematol Malig Rep 4:167-174.

Pombo-de-Oliveira MS and Andrade FG (2016) Early-age acute leukemia revisiting two decades of the Brazilian Collaborative Study Group. Arch Med Res 47:593-606.

Pombo-de-Oliveira MS and Koifman S (2006) Infant acute leukemia and maternal exposures during pregnancy. Cancer Epidemiol Biomarkers Prev 15:2336-2341.

Santos-Rebouças CB, Fintelman-Rodrigues N, Jensen LR, Kuss AW, Ribeiro MG, Campos M Jr, Santos JM and Pimentel MM (2011) A novel nonsense mutation in KDM5C/JARID1C gene causing intellectual disability, short stature and speech delay. Neurosci Lett 498:67-71.

Shao N, Jiang WY, Qiao D, Zhang SG, Wu Y, Zhang XX, Hua LX, Ding Y and Feng NH (2013) An updated meta-analysis of XRCC4 polymorphisms and cancer risk based on 31 casecontrol studies. Cancer Biomark 12:37-47.

Shao N, Li J, Wu HC, Tseng HC, Wang CH, Lin CC, Tsai CW, Liang SY, Wang CL and Bau DT (2014) Role of the functional variant $(2652 \mathrm{~T}>\mathrm{G})$ in the XRCC4 promoter in prostate cancer. Mol Biol Rep 41:7463-7470.

Simsek D and Jasin M (2010) Alternative end-joining is suppressed by the canonical NHEJ component Xrcc4-ligase IV during chromosomal translocation formation. Nat Struct Mol Biol 17:hhh410-416.

Slany RK (2009) The molecular biology of mixed lineage leukemia. Haematologica 94:984-993.

Tsai YY, Bau DT, Chiang CC, Cheng YW, Tseng SH, Tsai FJ (2007) Pterygium and genetic polymorphism of DNA (double strand break) repair gene Ku70. Mol Vis 13:1436-1440. 
Wang GS and Cooper TA (2007) Splicing in disease: Disruption of the splicing code and the decoding machinery. Nat Rev Genet 8:749-761.

Wu KH., Wang CH, Yang YL, Peng CT, Lin WD, Tsai FJ, Lin DT and Bau DT (2010) Significant Association of XRCC4 Single Nucleotide Polymorphisms with Childhood Leukemia in Taiwan. Anticancer Res 30:529-534.

\section{Internet Resourses}

HSF - Human Splicing Finder version 3.1 software, http://www. umd.be/HSF3/index.html (January, 2019).

\section{Supplementary material}

The following online material is available for this article:

Table S1 - Allele and genotype frequencies of XRCC6 rs5751129, XRCC4 rs6869366 and XRCC4 rs28360071 in cases and controls.
Table S2 - Genotype frequencies of XRCC6 rs5751129 in EAL subtypes and KMT2A status.

Table S3 - Genotype frequencies of XRCC4 rs6869366 in EAL subtypes and KMT2A status.

Figure S1 - Differential levels of XRCC4 mRNA in EAL bone marrow samples.

Figure S2 - In silico predictions for XRCC4 rs28360071 polymorphism (NM 022550.3:c.315+31090del30).

Figure S3 - Sequencing of bone marrow XRCC4 cDNA of patients with EAL.

Associate Editor: Maria Luiza Petzl-Erler

License information: This is an open-access article distributed under the terms of the Creative Commons Attribution License (type CC-BY), which permits unrestricted use, distribution and reproduction in any medium, provided the original article is properly cited. 